\title{
Dependencia y escasez de papel en las colonias hispanoamericanas
}

\author{
Dependência e escassez de papel nas colônias \\ hispano-americanas \\ Dependence and scarcity of paper in the colo- \\ nies hispanic american
}

José Carlos Balmaceda-Abrate Socio fundador y vocal de la Asociación Hispánica de Historia del Papel (AHHP). Madrid (España). Consejero científico de la Fondazione Fedrigoni Fabriano. Scienzia e arte della carta (FFF). Fabriano (Italia).

E-mail: jcbalmaced@hotmail.com

ORCID: https://orcid.org/0000-0001-5132-6535

\section{RESUMEN:}

La corona española se encontró con una dificultad fundamental, la falta de papel para administrar y evangelizar sus inmensos territorios de ultramar. Sin industrias papeleras suficientes, dependió durante tres siglos del papel que producía o distribuía Génova. Carlos III propiciará el desarrollo y la producción nacional hasta alcanzar la competitividad en el siglo XIX.

Palabras clave: Papel. Filigranas. Libros. Hispanoamérica. España. Génova.

RESUMO:

A coroa espanhola enfrentou uma dificuldade fundamental: a falta de papel para administrar e evangelizar seus imensos territórios ultramarinos. Sem indústrias de papel suficientes, dependeu, ao longo de três séculos, do papel produzido ou distribuído por Gênova. Carlos III promoverá o desenvolvimento e a produção nacional até atingir a competitividade no século XIX.

Palavras-chave: Papel. Marcas d'água. Livros. América Latina. Espanha. Gênova.

BALMACEDA-ABRATE, José Carlos. Dependencia y escasez de papel en las colonias hispanoamericanas. PÓS:Revista do Programa de Pós-graduação em Artes da EBA/UFMG. v. 11, n. 22, mai-ago. 2021 Disponível em < $\underline{\text { https://doi.org/10.35699/2237-5864.2021.25676 }>~}$ 


\section{ABSTRACT:}

The Spanish crown encountered a fundamental difficulty; the lack of paper to administer and evangelize its immense overseas territories. Without sufficient paper industries, it depended for three centuries on the paper produced or distributed by Genoa. Carlos III will promote development and national production until reaching competitiveness in the 19th century.

Keywords: Paper. Watermarks. Books. Latin America. Spain. Genoa.

Artigo recebido em: $11 / 10 / 2020$ Artigo aprovado em: 02/02/2021

BALMACEDA-ABRATE, José Carlos. Dependencia y escasez de papel en las colonias hispanoamericanas. PÓS:Revista do Programa de Pós-graduação em Artes da EBA/UFMG. v. 11, n. 22, mai-ago. 2021 Disponível em < $\underline{\text { https://doi.org/10.35699/2237-5864.2021.25676 }>}$ 


\section{Introducción}

Los descubrimientos de los navegantes abrieron espacios al comercio mundial a la vez que revolucionaron la imagen medieval del mundo. La imprenta y su principal vehículo, el papel, serán la esencia misma de la civilización. La galaxia Gutenberg generará a su alrededor no sólo a los técnicos de la imprenta. Estarán también incluidos los fundidores de tipos; el personal para la atención de las prensas, la compra y la elección del papel; encuadernadores, entre otros. Estarán convocados, del mismo modo, los grabadores, los escritores, los músicos, los científicos, los inventores, los arquitectos etc. Se propiciará entonces la aparición del papel de color y los marmolados, que llegarán a su esplendor en el XVII.

La imprenta permitirá el ascenso de las religiones basadas en la lectura de la Biblia, y que éstas introduzcan a campesinos y burgueses en las letras. Se generalizará la representación de la imprenta, recurriendo, a veces, a la simbología para ello (Fig. 1).

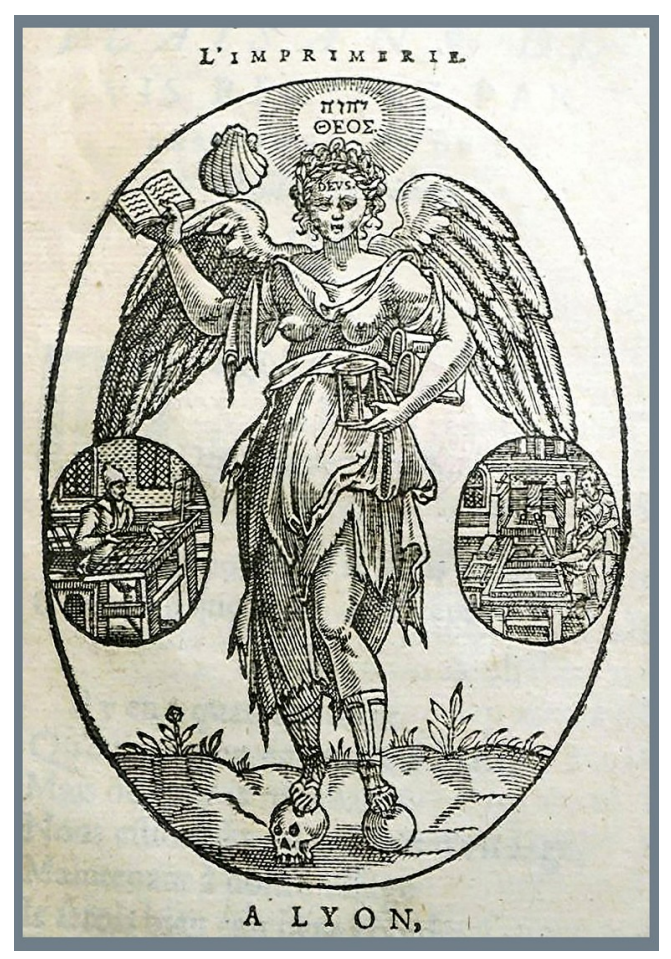

Fig. 1 - L'Imprimerie (Alegoría). Grabado xilográfico ovalado incluido en: Les plaisants devis, Seigneur de la Coquille. Lyon, 1585.

Fuente: Universal Short Title Catalogue (USTC). Disponible en: https://www.ustc.ac.uk/editions/56600.

BALMACEDA-ABRATE, José Carlos. Dependencia y escasez de papel en las colonias hispanoamericanas. PÓS:Revista do Programa de Pós-graduação em Artes da EBA/UFMG. v. 11, n. 22, mai-ago. 2021 Disponível em < https://doi.org/10.35699/2237-5864.2021.25676 $>$ 
Aparecerá el papel impreso para trasmitir ideologías y política, ya sea en manifiestos, panfletos, libelos, canciones y llegando al papel diario para comunicar al pueblo noticias inspiradas en la actualidad.' Sólo en París, durante el siglo XVII, según el impresor Antoine Vitré, se necesitaba entre 500.000 y 1.500 .000 pliegos de papel por día, y en el XVIII, debido a la publicación de L'Encyclopedie, el costo del papel aumentará un $67 \%$.

Debido a la invención de la imprenta, también se hará apremiante, a partir del XVI, la demanda de papel en España. La carencia de este producto allí debemos atribuirla a la falta de producción y de obreros especializados, pero también a las persecuciones de artesanos judíos, que serán acogidos por la ciudad italiana de Génova, futura proveedora del papel a la corona española. Aunque por causas de producción insuficiente ocurrió con los papeleros árabes del Levante, lo que va a generar negativas consecuencias para la industria papelera española, ya muy mermada, que se verá arrollada por la competencia italiana.

Las fábricas ya existentes, con su incipiente producción, no lograban abastecer la demanda interna de papel y menos aún la de sus colonias, como veremos más adelante, así que tampoco alcanzaban a proveerlo para la publicación de libros y de bulas con la calidad que se exigía. En los siglos XVI y XVII, un 80\% (como mínimo) de la población española no tenía acceso al libro impreso debido a su precio, y la causa de ello era, entre otras, el costo del papel.

Durante el siglo XVI, España recurrió a otros países para la impresión de libros; Italia editaba libros en castellano en imprentas de, como mínimo, diez ciudades, siendo Venecia, Roma y Milán las principales. También Francia lo hacía, sobre todo en las imprentas de París y las de Lyon, que se especializaban en libros litúrgicos. Este país, con sus exportaciones de papel y libros a España, cubrió gran parte de este comercio desde el siglo XV. Nantes fue un gran centro de distribución de papel hacia las ciudades de Bilbao, San Sebastián, Sevilla y Lisboa. Hubo también envíos desde La Rochela y Thiers, que seguían una ruta por tierra hasta Nantes y luego por vía marítima. A finales del siglo XVII, este comercio decayó; los impuestos y la competencia de los genoveses arruinaron a muchos papeleros franceses, que se vieron obligados a copiar las filigranas ligures - especialmente la de los Tres círculos, Escudo de Génova y El picador de toros (Fig. 2) - para vender a España parte de su producción (BALMACEDA, 2005; 2016).

BALMACEDA-ABRATE, José Carlos. Dependencia y escasez de papel en las colonias hispanoamericanas. PÓS:Revista do Programa de Pós-graduação em Artes da EBA/UFMG. v. 11, n. 22, mai-ago. 2021 Disponível em < $\underline{\text { https://doi.org/10.35699/2237-5864.2021.25676 }>}$ 


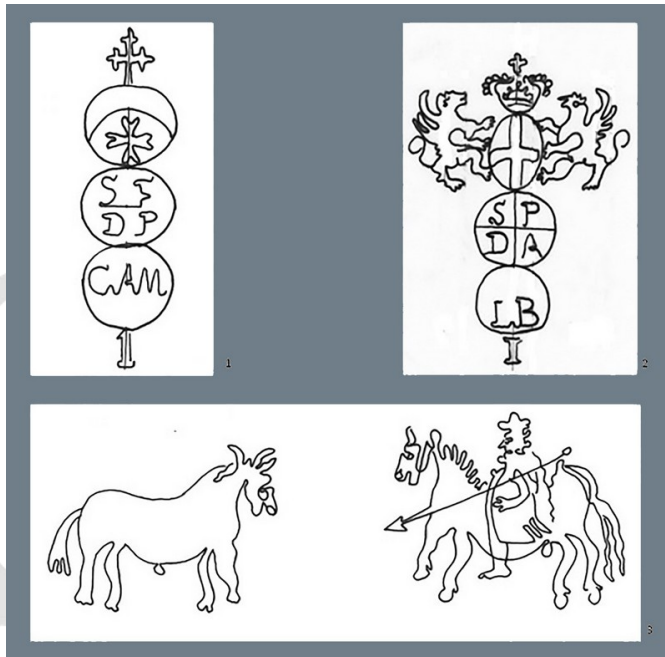

Fig. 2 - Filigranas del papel genovés vendido mayoritariamente a la Corona española.

Fuente: Corpus del autor. 1- Corpus B1767 s/f. 2- B0543/1710. 3- B1612/1773.

También se imprimieron libros españoles en Inglaterra, Alemania, Suiza, Bohemia y hasta en Salónica (Grecia), en círculos de judíos sefarditas (GALLEGO, 1999), aunque fueron, sin duda, los Países Bajos, cuando caen bajo el poder de los Austrias en 1519, el mayor centro emisor de libros en lengua castellana de la época. Así, Amberes se convierte en el centro más importante, seguido de Bruselas, Lovaina y Lieja. En la segunda mitad del siglo XVI, sin embargo, se detectan en España algunas mejoras técnicas; mejor papel y tipos redondos romanos de excelente fundición. No obstante, por haber durado poco, la producción del libro se verá ahogada por la competencia extranjera. Por otra parte, la aparición del grabado a buril, a principios del siglo XV, cuyo desarrollo se incrementará principalmente para la reproducción de dibujos y pinturas durante los siglos XVII y XVIII, se verá acompañada por la decadencia de la producción del libro español y el deterioro de materiales como el papel de escasa calidad a finales del siglo XVI. También las estampaciones sueltas, o sea, las imágenes impresas en papel, que eran verdaderos "crucifijos" para repartir entre los moriscos y americanos, sufrieron la escasez y la mala calidad del papel nacional.

Junto a los "pliegos poéticos", comienza también la floración, que en el siglo XVII será verdadera plaga con los llamados "remiendos" y "papeles de jornada", es decir, los impresos sin encuadernar (la hoja suelta con texto tipográfico), realizados teóricamente en un día. Por ejemplo, una bula, el terno o remetido y el remiendo a lo sumo de tres o cuatro pliegos. En este humilde soporte

BALMACEDA-ABRATE, José Carlos. Dependencia y escasez de papel en las colonias hispanoamericanas. PÓS:Revista do Programa de Pós-graduação em Artes da EBA/UFMG. v. 11, n. 22, mai-ago. 2021 Disponível em < $\underline{\text { https://doi.org/10.35699/2237-5864.2021.25676 }>}$ 
también florecerá una literatura funcional y de escasa calidad literaria - como alegatos jurídicos, memoriales y peticiones, currículum vitae, relaciones de fiestas, sermones, panegíricos, cartas con noticias, gacetas, órdenes, recibos etc. -, que igualmente consumía miles de resmas de papel.

\section{La escasez y carestía del papel en la imprenta española}

En el mundo del libro y de la estampación de la época, existió, además, una permanente alusión a la escasez y a la insuficiente calidad del papel, con lo cual se expresaba la necesidad de favorecer, por la Corona, la implantación de nuevos molinos papeleros en España y la mejora de los existentes.

El célebre arquitecto Juan de Herrera tuvo considerables problemas para "abrir" unas láminas sueltas a fin de difundir, calcográficamente, las maravillas de la fábrica de El Escorial. Las dificultades comenzaron con la búsqueda del papel especial para la estampación, que debía tener más cuerpo (ya que debía entrar a presión en las tallas abiertas en el metal y absorber la tinta, para lo que debía ser humedecido previamente). Herrera consiguió una autorización del Rey para importarlo de Italia, pues en España no lo encontraba de esa característica. Inclusive concertó con Francisco Testa y Gerónimo Gaeta, impresores de esa nacionalidad, para que lo abastecieran. Testa se había convertido en un hombre de negocios y comerciante de libros y grabados. En 1580, se asocia con Pietro Paulo de Montalbergo y, juntos, organizan desde Barcelona, donde residían, la venta en Madrid de 3.500 grabados estampados en Roma e importados por Sevilla (GALLEGO, 1999).

BALMACEDA-ABRATE, José Carlos. Dependencia y escasez de papel en las colonias hispanoamericanas. PÓS:Revista do Programa de Pós-graduação em Artes da EBA/UFMG. v. 11, n. 22, mai-ago. 2021 Disponível em < $\underline{\text { https://doi.org/10.35699/2237-5864.2021.25676 }>~}$ 


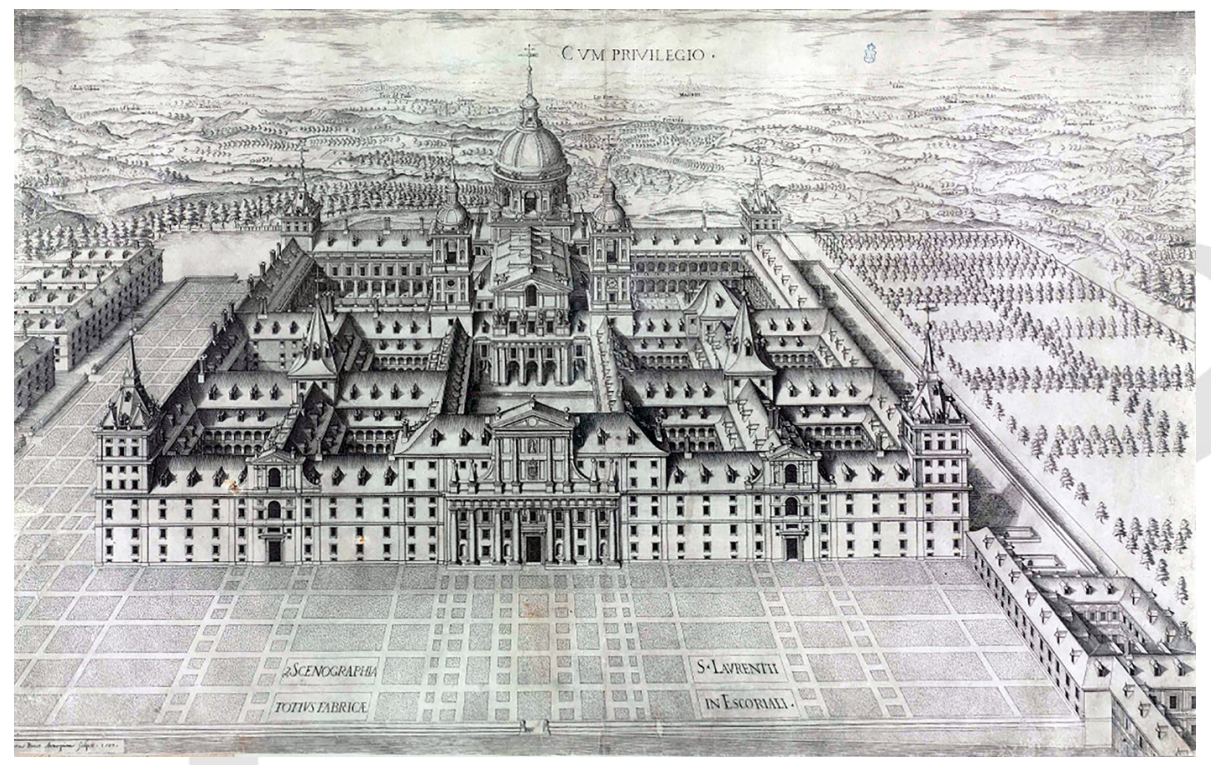

Fig. 3 - Perspectiva general de todo el edifício, por Petrus Perret (Bélgica), 1587. [Séptimo Diseño, Biblioteca Nacional, Madrid]. Buril sobre cobre.

Fuente: Biblioteca Digital Hispánica (BNE).

Disponible en: $\underline{\text { http://bdh-rd.bne.es/viewer.vm?id=0000025475 }}$

La estampación se concretó el 5 de agosto de 1587, y Herrera entregó los papeles para estampar las 13 planchas (Fig. 3) $)^{2}$ clasificados en tres formatos; los grandes en "imperial", los medianos en "papel real", y los pequeños en "medio pliego del real".

Sin embargo, debemos decir que a fines del XVII, a pesar de lo apuntado, el papel para la estampa se producía solo en algunos molinos catalanes, ${ }^{4}$ aunque su consumo era regional y la producción insuficiente para exportarlo a otros lugares de la Península.

La principal dificultad que encontró el monopolio estatal, una vez constituido, fue la inexistencia en España, y menos todavía en Nueva España y el resto de las colonias (donde no estaba permitido producirlo), de una industria papelera que suministrase el papel suficiente para el papel sellado (a partir de 1637) y de las diferentes calidades para uso general: imprentas, tabaco, estrazas etc. (BALMACEDA, 2015).

BALMACEDA-ABRATE, José Carlos. Dependencia y escasez de papel en las colonias hispanoamericanas. PÓS:Revista do Programa de Pós-graduação em Artes da EBA/UFMG. v. 11, n. 22, mai-ago. 2021 Disponível em < https://doi.org/10.35699/2237-5864.2021.25676 $>$ 


\section{La falta de papel de calidad para la impresión del Rezo}

Mucho después, durante el siglo XVIII, las Academias de Madrid y Valencia seguían requiriendo papeles de calidad, insuficientes en la fabricación española, para los ejercicios de pensados de pintura en la $2^{a}$ y $3^{a}$ clase - hechos en un pliego de papel holandés y en un medio pliego de papel del formato imperial -, y de impronta o boceto - que se hacían siempre en formato imperial (IZQUIERDO, 1975) (Fig. 4).

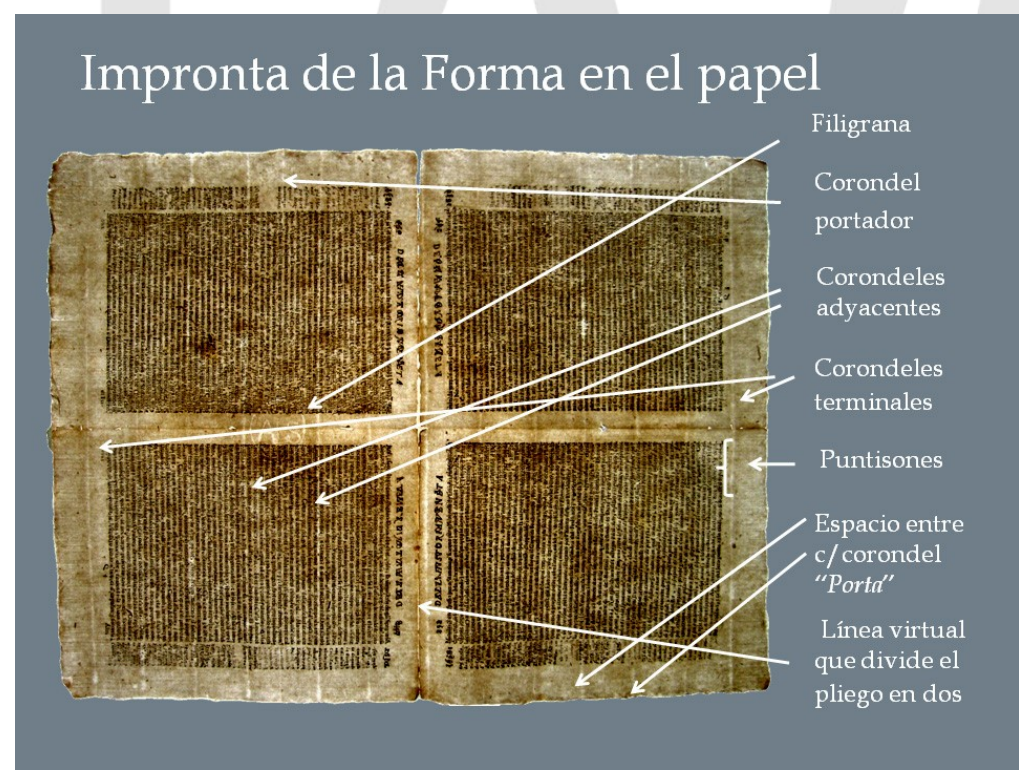

Fig. 4 - Pliego con los elementos constitutivos de toda hoja de papel hecho a mano (1680), vista por transparencia.

Fuente: BALMACEDA, Patina. n 16. Madrid. 2011 p. 166.

Por otra parte, se creaban problemas (debido a las diferentes autorizaciones otorgadas a los distintos grupos sociales) para obtener este soporte importado. En 1715, cuando se les renueva el privilegio a los ciegos para que no paguen los repartimientos y contribuciones, afirman que son discriminados con la calidad del papel de estracilla y ordinario que se les provee, comparándolo con el papel fino, el de mejor calidad producida en el molino de El Paular de Madrid, que reciben los impresores.

BALMACEDA-ABRATE, José Carlos. Dependencia y escasez de papel en las colonias hispanoamericanas. PÓS:Revista do Programa de Pós-graduação em Artes da EBA/UFMG. v. 11, n. 22, mai-ago. 2021 Disponível em < $\underline{\text { https://doi.org/10.35699/2237-5864.2021.25676 }>~}$ 
También se concedió un curioso privilegio, en mayo de 1719, a la Imprenta de Música de Madrid, a cargo de José de Torres, que se había establecido 3 años antes como organista principal en la Capilla Real. Se trataba principalmente de una exención de derechos sobre el papel importado, concretamente sobre 16 balones de papel ordinario, 12 de marquilla, 8 de marca mayor y 4 de Imperial, o sea, 1.000 resmas para cada año.

Asimismo, la justificación para otorgar el privilegio al colegio de las Niñas del Amparo para imprimir el 17 de diciembre de 1749 (REYES GÓMEZ, 2000), fue evitar, entre otros problemas,

que los autores no fueran a otros países, porque se beneficiarían del buen papel y de costeadores que asumían los riesgos, y porque las obras de importancia, y de muchos tomos ya se imprimían o reimprimían fuera de España. (LÓPEZ OLIVER, 1729).

Es tan ilustrativa la polémica sobre la falta de papel y la incapacidad de producirlo en España en la cantidad y calidad solicitada por los autores e impresores, que, durante mucho tiempo, en la primera mitad del XVIII, se discutió y se promovió la propuesta para la impresión del Rezo. Ante esta preocupación, Felipe V solicita a El Escorial, a principios de $1717,{ }^{5}$ los medios para establecer una imprenta del Rezo. El prior Eugenio de la Llave le respondió el 14 de febrero con un memorial donde expresa sus condiciones. En el punto tercero señala que:

Debido a la mala calidad del papel en España, se tendrían que establecer molinos y rehabilitar los del Escorial, que se arruinaron porque espantaban la caza del Rey, para lo cual, con el fin de que no se volviera a repetir perjuicio, se tendría que dividir el bosque en dos levantando un muro [...].

Y en el punto cuarto solicita el derecho de tanteo de trapos y papel libre de impuestos, aunque se hubiera de traerlo del extranjero. ${ }^{6}$

Estas propuestas no llegaron a nada, según el Memorial del Monasterio al Gobernador del Consejo de 1729. ${ }^{7}$ Asimismo, en ese año y en propuestas similares a las de 1717, El Escorial pide al Rey que, "como hay dueños de molinos que afirman que se puede hacer papel de calidad, el monarca debe ordenarles que lo hagan y [ellos] lo comprarán".

Hubo otras publicaciones del bloque formado por las Santas Iglesias separadas, ${ }^{8}$ tal el caso de las de Córdoba y Sevilla, que entregan al gobernador del Consejo, en septiembre de 1728, nueve ejemplares de misales y breviarios de Valencia a la mitad o la tercera parte del precio, unos

BALMACEDA-ABRATE, José Carlos. Dependencia y escasez de papel en las colonias hispanoamericanas. PÓS:Revista do Programa de Pós-graduação em Artes da EBA/UFMG. v. 11, n. 22, mai-ago. 2021 Disponível em < $\underline{\text { https://doi.org/10.35699/2237-5864.2021.25676 }>}$ 
impresos en papel español y otros en papel extranjero. Se afirmaba, además, que con estos bajos precios se harían libros correctos y con papel español de mejor calidad, y así se impediría la salida de más de "cuarenta mil doblones" al año.

También se registran acusaciones a las propuestas de La Llave, que solicitaba privilegios y exenciones para los oficiales y operarios extranjeros en las fábricas de papel y en las imprentas. Las negativas sólo conducían a imposibilitar o dificultar la deseada imprenta del Rezo en España, en vez de facilitarla, y tampoco se potenciaba la industria del papel (LÓPEZ OLIVER, 1729).

En una otra propuesta, El Monasterio retaba al impresor valenciano Antonio Bordazár a que viera el material, o sea, el papel, y que los imprimiera al precio que decía López Oliver, lo que favorecería, sin duda, a los molinos de papel de La Adrada.

Por su parte, el fabricante José Soler, que tenía a su cargo los tres molinos de Cuenca, reconocía que el papel era una carencia tradicional de España y que "se elabora de baja calidad" (LÓPEZ OLIVER, 1729). Confirma, además, la existencia de los siguientes molinos: del Arco, en Segovia; La Adrada, en Ávila; de Francos, cerca de Santiago de Compostela; de Beteta, en Cuenca; la fábrica de Algeciras, en Cádiz; la de Nuevo Baztán (de Juan de Goyeneche) y El Paular, en Madrid. Menciona también sitios en Capellades, Igualada, Figueras y Manresa, en Cataluña, y otros en Mallorca, Granada, Sigüenza, Valladolid y Toledo. Asimismo, agrega que junto con Goyeneche pueden ofrecer una entrega de 5.000 resmas cada uno por año. También demanda al monarca la franquicia de derechos de puertos, aduanas, alcabalas etc. para el papel que se consuma en la oficina.

El 16 de abril de 1732, Felipe $V$ aprueba el decreto para imprimir el Rezo en España. En un nuevo comunicado de El Escorial, ahora a cargo de Fr. Juan de la Puebla, con fecha del 22 de junio del mismo año, se reitera que "El Rey debe ordenar construir fábricas de papel, pues no hay para el Rezo en España". ${ }^{9}$ Se insiste, igualmente, en el derecho de tanteo, ante la escasez de trapos, o la ida al extranjero para la compra, logrando así la calidad del de Génova. Y también se solicita la contratación de maestros y oficiales latinos inteligentes. La reincidencia en el pedido de mano de obra extranjera nos afirma que el problema de la calidad radicaba principalmente en la falta de técnicos que pusieran en práctica sus conocimientos en los molinos hispanos (REYES GÓMEZ, 2000, p. 449).

BALMACEDA-ABRATE, José Carlos. Dependencia y escasez de papel en las colonias hispanoamericanas. PÓS:Revista do Programa de Pós-graduação em Artes da EBA/UFMG. v. 11, n. 22, mai-ago. 2021 Disponível em < $\underline{\text { https://doi.org/10.35699/2237-5864.2021.25676 }>~}$ 
Bordazár (1732), por su parte, insiste en que hay facilidades con el papel, debido a que hay más de cuarenta molinos, pero no los identifica. El monasterio de El Escorial, de su lado, defiende a capa y espada el privilegio real que le había sido prorrogado sucesivamente, y que tenía el peso de un siglo y medio de práctica.

Años más tarde, ya con Fernando VI, un proyecto de Luis de Cueto, fechado el 3 de noviembre de 1747 para Aragón, Cataluña, Valencia, Navarra y Mallorca, pretendía establecer la mejor imprenta de España, debido a que, si el molino de la Compañía no elaboraba más de 16.000 mil resmas al año, se podría recurrir al producido en la fábrica de Capellades, o cualquiera otra de Cataluña. Además, se insistía que se impidiera la exportación del trapo de Aragón y que se favoreciera la compra en los otros territorios españoles. Este proyecto también fue rechazado.

Por su parte, el impresor valenciano José de Orga presenta dos memoriales más, uno en $1748^{10}$ y el otro en $1749,{ }^{11}$ para la formación de una compañía para la impresión del Rezo, donde insiste en el primero que el papel tiene que ser nacional con la misma calidad del fioreto, de Génova, y del marquilla de otros lugares que no indica. En el segundo memorial, ubicándose más en la realidad de la industria papelera existente, explica que el papel será de las fábricas nacionales siempre que sea de calidad y que, además, la Compañía podrá hacer ajustes con los dueños de las fábricas para que tengan derecho de tanteo al adquirir los trapos y las carnazas para hacer la cola. Asimismo, declara que el papel, igual que los libros, será libre de impuestos (según las leyes de los años 1639 y 1720) y encarga que la Compañía aproveche el agua de ríos y acequias para establecer nuevas fábricas de papel donde puedan instalarse. Tampoco tuvo éxito José de Orga, y el Monasterio de El Escorial salió favorecido, o mejor dicho, siguió adelante. Lamentablemente, el trapo se seguirá llevando a Génova.

La real orden del 5 de junio de $1751^{12}$ refleja asimismo la preocupación por la calidad y demuestra el deseo de que se fomenten y perfeccionen las fábricas de papel. La carencia y la baja calidad del papel que encontraban los impresores quedan registradas con el siguiente ejemplo, de 1756, cuando el famoso impresor Joaquín lbarra es llamado a declarar sobre la edición de un catón de dudosa calidad. Éste alegó que el papel empleado le parecía "entrefino", aunque podría pasar por papel de la fábrica del Nuevo Baztán - con el que se imprimía la Gaceta -, y afirma que el de la impresión de 1755 era de mejor calidad, atribuyendo unos pliegos a la fábrica de Zaragoza y otros a

BALMACEDA-ABRATE, José Carlos. Dependencia y escasez de papel en las colonias hispanoamericanas. PÓS:Revista do Programa de Pós-graduação em Artes da EBA/UFMG. v. 11, n. 22, mai-ago. 2021 Disponível em < $\underline{\text { https://doi.org/10.35699/2237-5864.2021.25676 }>}$ 
la de Los Heros, del obispado de Sigüenza. Como queda claro, era común emplear papel de varios molinos y procedencias en una misma edición, resultando, por lo tanto, en calidades desiguales (Fig.7).

El papel fino semejante al de Capellades comienza a tomarse como referencia y obligan a usarlo en todas las impresiones de libros, gacetas y cualquier otra impresión. También debería descartarse el "papel ordinario" (como se llamaba al usado en las imprentas) producido en otros molinos españoles. Si bien la calidad encarecía el precio del libro, se castigaban a los infractores con multas que iban desde la perdida de las obras a cincuenta ducados, agravadas con los reincidentes. ${ }^{13}$

La respuesta inmediata de los impresores no se hizo esperar y es sumamente interesante y afirmativa de todo lo que hemos expuesto sobre la necesidad de la calidad y la abundancia del papel fino de Génova, ya que el primer problema planteado para cumplir con estas exigencias fue la imposibilidad de usar el papel de Capellades. Según declaraciones del Juez de Imprentas, Juan Curiel, en Capellades se hacían tres suertes de papel fino: el de primera iba a la Corte para proveer al Palacio; el de segunda, llamado "entre fino", se gastaban 10.200 resmas en el papel sellado; y el tercero era de una calidad tan inferior a los otros dos que no se tomaba en cuenta. Asimismo, las demás fábricas también tenían papel con la misma diferencia de clases, pero la primera no era similar a la de Capellades, sí la segunda. Esta calidad era la que fabricaban las fábricas de Cuenca y Gorquer. Según lo informado por Curiel, podemos deducir que la suerte del papel fino que iba a la corte era el que elaboraba la familia Guarro y que usaba el hijo del rey. Además, se dice en la Memoria de los impresores (de Madrid y Sevilla de 1751) que en España tan sólo existían las nombradas fábricas de papel en Cataluña, lo que [obviamente] era inexacto.

Mientras tanto, en Madrid había cien prensas en funcionamiento, que sí pretendían hacer la impresión en papel fino como se exigía, pero habría que importarlo, ya que era muy escaso, de regular calidad y a un precio excesivo. ${ }^{14}$ Esta consideración contradecía la intención de fomentar las fábricas en España. Finalmente, según las resoluciones reales del 28 de junio de 1753 y del 20 de noviembre de 1755 , se eligió el papel de segunda clase, o sea, el blanco ordinario, común a las fábricas españolas mencionadas más arriba y que seguidamente informamos de su producción.

BALMACEDA-ABRATE, José Carlos. Dependencia y escasez de papel en las colonias hispanoamericanas. PÓS:Revista do Programa de Pós-graduação em Artes da EBA/UFMG. v. 11, n. 22, mai-ago. 2021 Disponível em < $\underline{\text { https://doi.org/10.35699/2237-5864.2021.25676 }>~}$ 
En 1757, la escasez continuaba. Los libreros sevillanos pedían autorización para usar el papel francés o italiano, debido a que el español era de calidad irregular y no había ni para la mitad de las necesidades de la ciudad. ${ }^{15}$

Finalmente, en 1763, la Real Compañía de Impresores y Libreros del Reino firmará un convenio con las autoridades de El Escorial, que no perderá los privilegios de los últimos 200 años. Sí lo hará con la extracción de caudales al extranjero. Se reiteraba en el punto cinco, además, que el papel debería ser nacional y de primera calidad. A partir de 1764, las modificaciones de la legislación y la firme determinación de Carlos III resuelven que la impresión de los libros de rezo se realice por los españoles y en su territorio. No obstante, la revisión y la aplicación de esta ley causó problemas a muchos impresores por las mismas causas apuntadas anteriormente.

\section{El impuesto del papel sellado acrecienta la falta de papel en las colonias}

La Pragmática del 15 de diciembre de 1636, de Felipe IV, decretó la introducción del papel sellado, y con fuerza de ley se ordenaba su entrada en vigor en España desde el 1 de enero 1637. Con la Pragmática del 28 de diciembre de 1638, se establecía, a su vez, a partir del 1 de enero de 1640, la entrada en vigor en las colonias.

Entonces, la Junta de Sellos valoró los gastos necesarios para implementar el impuesto del papel sellado, y para los primeros gastos se necesitaban 100.000 ducados, que correspondían al costo del papel, la impresión y la distribución. El cálculo anual de papel fue estimado entre 40 o 50 mil resmas. Carlos Strata, Lelio Imbrea, Manuel de Paz y Jorge de Paz de Silveira eran los cuatro banqueros genoveses más importantes de la época y fueron los que aportaron los 900.000 escudos necesarios para solucionar los problemas económicos en la Corte, entre ellos el papel sellado. Estos recibirían 468.000 ducados, distribuidos según el aporte de cada uno del primer dinero que produjese el nuevo impuesto. ${ }^{16}$ Fue nombrado tesorero general el italiano Julio César Scacuola. Asimismo, la Corona también tenía empeñado el producto del nuevo impuesto por varios años, ya que se habían prometido 307.500 escudos al factor principal; el poderoso banquero genovés Bartolomé Spinola, a cuenta de la provisión que, "por vía de factoría", había prestado - la inmensa cantidad de 1.200.000 escudos para cubrir necesidades del reino. ${ }^{17}$

BALMACEDA-ABRATE, José Carlos. Dependencia y escasez de papel en las colonias hispanoamericanas. PÓS:Revista do Programa de Pós-graduação em Artes da EBA/UFMG. v. 11, n. 22, mai-ago. 2021 Disponível em < $\underline{\text { https://doi.org/10.35699/2237-5864.2021.25676 }}>$ 
Además, la escasez del papel se debía algunas veces al sustraído, junto a otros géneros, por la piratería. Tal lo que sucedió ante la implantación del papel sellado en Filipinas, que, al carecer del papel enviado por Castilla por estas causas, selló en papel fabricado en China, sugiriendo la conveniencia de usarlo por la facilidad de obtenerlo y por su bajo costo. El gobernador y capitán general de Filipinas da cuenta de la acogida que tuvo en las islas el papel sellado y porqué se selló con el papel de China:

\begin{abstract}
La mayor dificultad que ofreció la Junta fue no haber traído el Papel Sellado de Castilla, como Vuestra Majestad fue servido avisarlo, que se presupone a descuido de los ministros, venciese con hacer sellar, con los sellos que vinieron, en papel de China que acá vale muy barato y se ahorra a Vuestra Majestad mucho dinero. En que no venga de la China sólo una dificultad se me ha ofrecido, que como los chinos son tan finos en contrahacer cualquiera cosa de que usamos los castellanos, lo pueden traer de su reino sellado y venderle a los escribanos y personas que es forzoso lo compren en la sala y caja dedicada para dicho papel, y el remedio que he hallado para obviar éste inconveniente sin que les valga el contrahacer dicho sello por ningún caso. Con todo lo cual está excusado el que Vuestra Majestad mande enviar papel desde Castilla de 2 en 2 años, ni los años, pues en cada uno acá se harán nuevos por el inconveniente apuntado, como viene la Bula, pues acá lo hay, como apuntado tengo, tan barato como en España pueda estar, una resma no costará aquí un vellón. ${ }^{18}$
\end{abstract}

Lamentablemente, no tuvo ninguna apreciación lo dicho y se siguió esperando el papel enviado desde la península, a pesar que en un primer momento, entre otros problemas, era conseguir el papel para sellar a un buen precio.

En 1617, el establecimiento del gravamen a la fabricación, la importación y la explotación del papel, aprobado por las Cortes en octubre de 1616, quedó en una blanca (moneda antigua de vellón, que tuvo distintos valores según la época) por cada pliego de papel blanco ordinario y cuatro maravedíes por cada mano de papel de estraza. Se agravaba ahora con la ampliación de 4 reales por resma para la contribución a pagar el servicio de los dos millones y medio, impuesto que se suprimió en un primer momento cuando se trató el asiento con Julio Cesar Scacuola. Este se comprometió a pagar la impresión, luego se decidió volver atrás, dejando sin efecto la supresión del impuesto ${ }^{19}$. Posteriormente se concretó un nuevo acuerdo con otro proveedor.

Años después, Nicolás Grasso ${ }^{20}$ ofrecía al Consejo traer y entregar, entre julio y setiembre de 1637, 20.000 resmas de papel genovés en cuatro remesas a 23 reales y medio, igual precio que el que había propuesto Scacuola. Además, en una de las condiciones sobre la calidad del papel blanco

BALMACEDA-ABRATE, José Carlos. Dependencia y escasez de papel en las colonias hispanoamericanas. PÓS:Revista do Programa de Pós-graduação em Artes da EBA/UFMG. v. 11, n. 22, mai-ago. 2021 Disponível em < $\underline{\text { https://doi.org/10.35699/2237-5864.2021.25676 }>~}$ 
para sellar, él dice "que es en la forma que viene de la ciudad de Génova y es uso y costumbre de venderse en esta corte". ${ }^{21}$ Tres años después, se repite un nuevo pedido de 281 balones ${ }^{22}$ a razón de 24 resmas cada balón de papel blanco de Génova, que equivale a 6.745 resmas, $^{23}$ y se ordena la entrega a la sala del papel sellado del Consejo de Indias.

La exportación de papel a América desde Sevilla y Cádiz en el periodo entre 1650 y 1699 fue de 839.592 resmas, que repartidas por año nos da un promedio de 16.792 resmas, o sea, 8.391 .000 pliegos (BALMACEDA, 2005). Cádiz fue el lugar que monopolizó el envío, con un 96,7\%, siendo casi nulo el envío desde Sevilla, con un 2,9\%. El gran consumidor fue Nueva España, con un 65\%, y el menor ha sido Puerto Rico, con 0,2\% (GARCÍA FUENTES, 1980). No obstante, estas cifras me parecen relativamente pequeñas y parciales si tenemos en cuenta la producción anual genovesa y su permanente incremento debido a las necesidades españolas.

Asimismo, desde un principio también se llevó el papel genovés a las fábricas de tabaco, mientras se procuraba el nacimiento de una industria papelera suficiente en el reino, fomentando, a su vez el incremento de las fábricas existentes en Cataluña, Valencia y Aragón, evitando así la sangría económica que debía afrontar abasteciéndose en el extranjero. La monopolización de la venta de tabaco en rama en 1764 y sus manufacturas en 1767 creó la necesidad de grandes cantidades de papel para los puros y cigarrillos, papel que debía reunir unas características especiales: "buen y parejo arder, hacer granito y ceniza blanca, sabor agradable, no contener materias ofensivas a la salud y ser propio para personas delicadas de la garganta". Se pidió, inicialmente, 80.000 resmas, que tampoco se pudieron cubrir con la producción española, recurriendo nuevamente a Génova, que sólo prometió entregar la cantidad de 3.000 resmas. Con esta carencia, se generó en 1766 la expedición de otra Real Cédula, ordenando la cooperación de los fabricantes para que este papel se hiciera en la Península y recomendando las especificaciones exigidas. Un año después, arribaron a Veracruz 56.690 resmas, de las cuales sólo 3.840 procedían de Génova (LENZ, 1990. 109). Tímidamente, se notaba el cambio que se producirá en los próximos años.

Para la protección, se recomendó que no se enviara el papel en cajones a las fábricas de tabaco, sino en balones cubiertos de lienzo crudo u otra protección con unas medidas de "seis varas" (0,836 metros) de largo. Igualmente, se exigió que los balones (24 resmas) se diferenciaran con las

BALMACEDA-ABRATE, José Carlos. Dependencia y escasez de papel en las colonias hispanoamericanas. PÓS:Revista do Programa de Pós-graduação em Artes da EBA/UFMG. v. 11, n. 22, mai-ago. 2021 Disponível em < $\underline{\text { https://doi.org/10.35699/2237-5864.2021.25676 }>}$ 
siguientes marcas: $R E Y C$ para el papel de Génova de primera clase; $R E Y D$ para el papel de Génova de segunda clase; REY para el papel comprado en Génova por cuenta de la Real Hacienda; REY $B$ para el papel de Barcelona y REYE para el papel de Valencia.

No obstante, faltaba mucho tiempo para prescindir del papel genovés, que siguió llegando a las colonias enviado por la corona y, muchas veces, por otros medios y otros proveedores de aquí y allá en abierta complicidad con el contrabando. Es evidente que las cifras del comercio oficial no reflejan la verdadera importancia que debió tener, en la masa global del comercio indiano, las transacciones de papel y de libros, géneros sobre los que pesaba una fuerte demanda; algo imposible de evaluar.

El historiador Domínguez Ortiz afirmaba sobre el contrabando que "no fueron los extranjeros, sino los españoles los primeros en practicarlo" (COMELLAS, 1992, p. 70). Además, la complicada reglamentación, ante la exclusión de Cádiz durante la época del monopolio de Sevilla, despertará la apetencia de eludirla, y son los comerciantes gaditanos (naturales de Cádiz) los que instauran el fraude en el comercio. Los extranjeros habían encontrado el fraude instalado en la navegación a Indias (VILLALOBOS, 1986; MOUTOUKIAS, 1988).

En 1721, Rodrigo Calderón, intendente de Galicia, indicaba que más de dos millones anuales costaba el papel que mandaba Génova para España e Hispanoamérica, fabricado en los más de 150 molinos que tenían los genoveses en el valle de Voltri, adonde llevaban desde España, en muchos navíos, un infinito número de fardos de trapos usados, de cuerdas y alpargatas viejas. Por otra parte, Santiago Quartino, vecino y comerciante de Cádiz, hijo del fabricante de papel genovés Juan Andrés Quartino, pidió permiso para llevar a Génova 1.500 quintales de trapos para que su padre fabricara el papel encargado. $O$ sea, el equivalente para producir 7.300 resmas de papel fino, que le fue autorizado.

Juan de Zubiarre, veedor de la Sala de Sellos, tenía indicado que podía vender los balones que sobraran de la impresión de sellos y las manos costeras de los 50 balones de papel blanco, con el fin de pagar a los arrieros que conducían el papel sellado a Sevilla e al convento del Carmen y los salarios atrasados de los ministros inferiores del papel sellado. ${ }^{24}$ Sorprende sospechosamente que se recurriera a estas operaciones para cubrir las deudas mencionadas, que eran pequeñas cantidades dada la magnitud económica del impuesto sellado, aunque quede clara la falta de

BALMACEDA-ABRATE, José Carlos. Dependencia y escasez de papel en las colonias hispanoamericanas. PÓS:Revista do Programa de Pós-graduação em Artes da EBA/UFMG. v. 11, n. 22, mai-ago. 2021 Disponível em $<$ https://doi.org/10.35699/2237-5864.2021.25676 $>$ 
caudales con la que se manejaba el impuesto y la dependencia con los prestamistas foráneos. Las manos costeras se componían de 25 pliegos en cada extremo de la resma, que sumaban la nada despreciable cantidad de 61.000 pliegos.

A mediados del siglo XVIII, los productos manufacturados enviados a América se elevaban al 54\%, siendo el $5 \%$ correspondiente al papel, del que seguía siendo el principal proveedor Génova. Debido a los beneficios de intercambio, este incremento del comercio hacia las colonias americanas enriquecía tanto al comprador como al comisionista español, sobre todo la región de Cataluña.

Es a partir del año 1766 que también comienza a ser enviado el papel valenciano. Ante las comparaciones de calidad a la que se veían obligados, los papeleros valencianos dirigían su rechazo hacia los papeleros genoveses, sencillamente porque, por ahora, les era imposible igualar su calidad, impuesta por los revisores. El intendente de Valencia prevenía a los fabricantes con esta comparación del papel genovés:

La diferencia corta que tiene, en lo fino y blancura, consiste mucha parte en que el de aquí está fresco, acabado de hacer, y el de Génova fioretto sentado de mucho tiempo, que cuando llegue a pasar de un año o más, se mejorará mucho, porque tomará asiento y unión la cola, para lo que en las fábricas extranjeras no se vende sino de un año para otro, a que se añade el bajo precio de 20 reales de vellón a que se paga la resma, cuando el fino se despacha por los mismos fabricantes a 32 reales de vellón, y es precio corriente el de 26 reales de vellón en el de la muestra de Génova. ${ }^{25}$

La evolución de la radicación de fábricas de papel en Valencia fue vertiginosa: de un molino en 1750, llegó a tener 38 en 1791, especializándose en el papel de fumar. La creciente producción española fomentada por Carlos III fue excluyendo el papel genovés y limitando hacia 1795 la venta a los comerciantes de Cádiz, que lo enviaban a las colonias. A partir de 1814, las naves genovesas comienzan a navegar más hacia América, comerciando directamente con las colonias, futuras flamantes repúblicas emancipadas, y renovando el rico y abundante comercio del papel. Sin embargo, en 1830, el número de fábricas de papel de Voltri disminuye a 100, de más de 150 que había a fines del siglo XVIII, 50 de las cuales estaban instaladas en la vecina Mele (Génova). España y

BALMACEDA-ABRATE, José Carlos. Dependencia y escasez de papel en las colonias hispanoamericanas. PÓS:Revista do Programa de Pós-graduação em Artes da EBA/UFMG. v. 11, n. 22, mai-ago. 2021 Disponível em < $\underline{\text { https://doi.org/10.35699/2237-5864.2021.25676 }>}$ 
sus colonias seguían consumiendo entre la mitad y la tercera parte de la producción anual de papel genovés, o sea, cerca de 260.000 resmas de papel blanco, cantidad que es válida para los siglos anteriores.

\section{La capacidad productiva de las fábricas de papel durante el siglo XVIII}

En la documentación presentada en el capítulo anterior, el fabricante de papel José Soler menciona que una de las partes interesadas afirma que las fábricas españolas poseen la capacidad de cumplir con las necesidades (en la cantidad y la calidad requeridas) para la impresión, y así alcanzan a suplir el arribado desde Génova. Por el contrario, la otra parte insiste en la carencia de esas condiciones en la fabricación local.

A continuación, anotamos la capacidad y la producción de estos molinos según la incompleta documentación existente, con la intención de presentar las efectivas posibilidades de llevar a cabo la empresa de la impresión del rezo, del papel sellado y las demás necesidades de este producto.

En la villa de La Adrada, provincia de Ávila, había varios molinos de papel a comienzos del siglo XVIII que, casi en régimen de exclusividad, fabricaban papel para la impresión de bulas de la Santa Cruzada. La producción era, sin embargo, insuficiente ante la demanda de la institución. En estos molinos, trabajó el genovés Félix Solesio, que se convertirá años después en el asentista de las reales fábricas de naipes de San Fernando de Henares, en Madrid, y de Macharaviaya, en Málaga. Él fue, además, creador del complejo papelero de Arroyo de la Miel-Benalmádena, en 1784 (BALMACEDA, 1998; 2004).

El molino de Francos, en Famarello (La Coruña), fue construido por los genoveses Bartolomé Piombino y Joseph Gambino (Fig. 5). Su producción fue de 20 resmas diarias, repartidas anualmente en 500 resmas de papel de primera, segunda y tercera suerte y 4.900 resmas de papel de la cuarta suerte. Éste papel sólo se utilizaba para "librar y embolatar tabaco", cumpliendo el contrato con la Renta del Tabaco de Galicia y principado de Asturias, y para especias, papel de estraza o de envolver. No se registró fabricación de la calidad florete.

BALMACEDA-ABRATE, José Carlos. Dependencia y escasez de papel en las colonias hispanoamericanas. PÓS:Revista do Programa de Pós-graduação em Artes da EBA/UFMG. v. 11, n. 22, mai-ago. 2021 Disponível em < https://doi.org/10.35699/2237-5864.2021.25676 $>$ 
El molino de Beteta, en la provincia de Cuenca, fue construido en 1709 por el Marqués de Ariza. En sus comienzos, produjo papel blanco común y luego papel fino. En 1738, producía 20 resmas diarias en sus dos tinas. El papel para imprenta se consumía en Cuenca, Salamanca y Madrid, y el fino, en Córdoba, Jaén y Murcia. Su precio era de 14 a 15 reales la resma de papel para imprimir; el "entrefino" salía a 18 reales y el fino a 22 reales. En 1792, el molino se encontraba en ruinas.

La más antigua referencia sobre producción de papel de la fábrica de Algeciras, provincia de Cádiz, es la de Pascual Madoz en su Diccionario geográfico-estadístico-histórico de España y sus posiciones de Ultramar, en 1846. La mención de López Oliver, 100 años antes, de una fábrica en esta localidad (así como menciones a otras localidades de Andalucía) propone una investigación. Una hipótesis es que la actividad de esta fábrica pudo estar interrumpida por largos periodos, o que su producción fuese de papel blanco ordinario y de estrazas, ya que tampoco es citada por otros autores contemporáneos ni por los anuarios y almanaques del siglo XIX. No obstante, son varios los molinos de Andalucía de esa época que fueron ignorados (BALMACEDA, 1998; 2001; 2015).

El Molino del Arco, en Segovia, también producía papel para la impresión, y por él pasaron varios maestros y oficiales genoveses, flamencos y franceses. En 1709, fabricaba papel fino, ordinario, para imprenta y marca mayor; ya en 1740, fabricaba papel "marquilla fina", común de impresión y de estanco o de envolver.

La fábrica del Nuevo Baztán (Fig. 5), ubicada en la Provincia de Toledo (que a partir de 1833 pertenecerá a Madrid), fue establecida en 1720 por Juan de Goyeneche, en el margen derecho del río Tajuña, a 2 kilómetros del municipio de Orusco. Este río era considerado por el propietario como una "principal alhaja", donde se alineaban, además, los molinos de trigo, los batanes de paños y todas las casas, las eras para cereales y los términos de las villas madrileñas de Ambite, Orusco y Carabaña. La instalación se hizo en este río aprovechando un antiguo batán, llamado "Vella-escusa”, que tenía arrendado el industrial vasco. ${ }^{26}$

BALMACEDA-ABRATE, José Carlos. Dependencia y escasez de papel en las colonias hispanoamericanas. PÓS:Revista do Programa de Pós-graduação em Artes da EBA/UFMG. v. 11, n. 22, mai-ago. 2021 Disponível em < $\underline{\text { https://doi.org/10.35699/2237-5864.2021.25676 }}>$ 


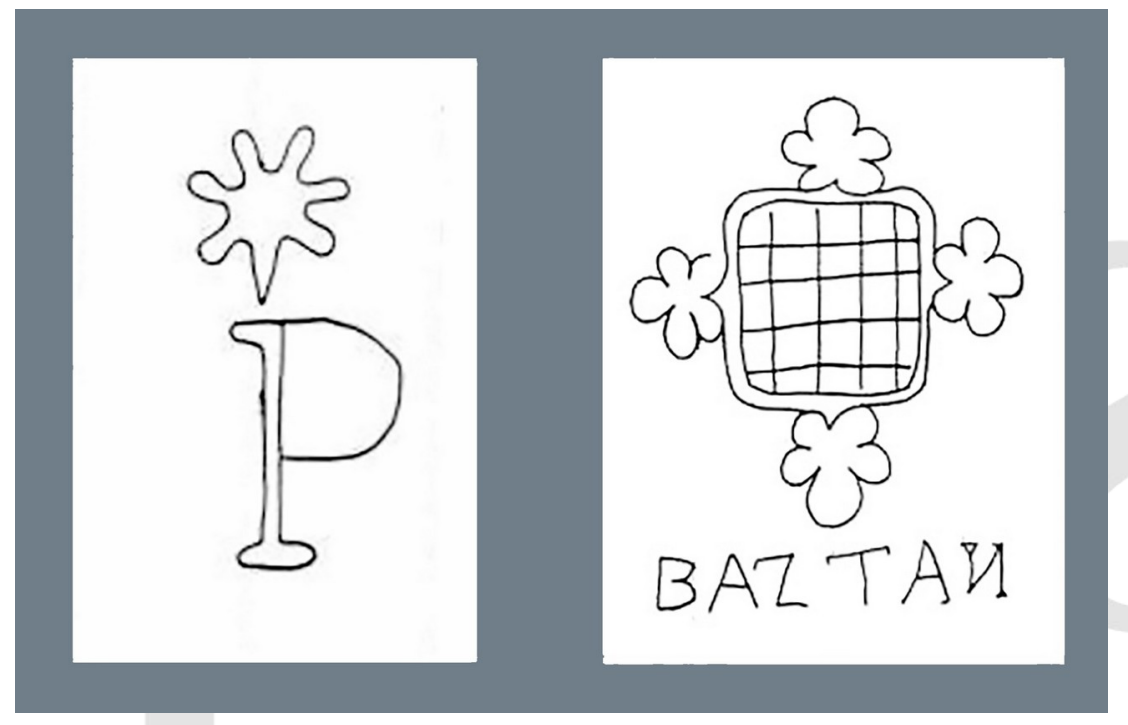

Fig. 5 - [lzquierda]: Filigrana de B. Piombino, papel de un impreso en Santiago de Compostela, en 1733; [Derecha]: Filigrana de Juan de Goyeneche, papel de un impreso de 1754. Fuente: Corpus de Gonzalo Gayoso Carreira (1994, t. II).

La fábrica del Nuevo Baztán fabricó papel fino, "entrefino" y de imprenta hasta 1745, cuando detuvo su producción por suspensión de las franquicias con las que se beneficiaba. Tres años más tarde, el hijo de Juan, Francisco Miguel, junto al Conde de Saceda y al Marqués de Belzunce, volvieron a poner corriente la fábrica. En 1760, ella funcionaba y contaba con 60 operarios, reconociendo la Corona la calidad del papel fabricado allí. Tres años más tarde con motivo de la renovación de las exenciones de impuestos, que le concederán nuevamente, esta vez, sólo por cinco años. En 1762, todas las demás fábricas del complejo se fueron arruinando; en 1765, la de papel estuvo a cargo del papelero Lorenzo Guarro; ${ }^{27}$ en 1778 , cerró definitivamente.

Respecto al molino de Mallorca, según registra un bando de 1757 (la primera información a que tuvimos acceso, salvo la de Soler), se desprende que tres años antes ya había una fábrica de papel en Palma cuyo propietario era el impresor real Ignacio Frau junto al librero Matías Fortuny, y que estaba a punto de desaparecer por falta de trapos. Frau tenía la concesión para proveérselo en la isla al precio acostumbrado. No obstante, los traperos lo seguían enviando a Cataluña. Ante las reclamaciones de Frau se prohibió la exportación del trapo mallorquín. En 1761, se concedió a Frau el privilegio de la adquisición de todo el trapo que precisara su fábrica, dejando sólo el sobrante a los catalanes. La producción anual era aproximada a las 4.000 resmas. Madoz informa, en el año de 1847, de otra fábrica en la isla, en Esporlas.

BALMACEDA-ABRATE, José Carlos. Dependencia y escasez de papel en las colonias hispanoamericanas. PÓS:Revista do Programa de Pós-graduação em Artes da EBA/UFMG. v. 11, n. 22, mai-ago. 2021 Disponível em < $\underline{\text { https://doi.org/10.35699/2237-5864.2021.25676 }>}$ 
La ciudad de Granada contó, a partir de 1830, con la instalación de dos molinos de papel por los hermanos genoveses Bonicelli. Creo que su mención en el mismo año por López Oliver obedecía al entusiasmo y al deseo de la producción que se haría en la flamante fábrica. No obstante, durante el siglo XIX se desarrollará considerablemente esta industria en la provincia.

Los molinos de Sigüenza, en la provincia de Guadalajara, eran conocidos con ese nombre porque estaban sólo a dos leguas de esta ciudad, ubicados en La Cabrera, sobre el río Dulce. Han sido registrados en 1733. Dos años después, la Real Cédula otorga franquicias a los hermanos Joseph y Tomas Romaní. El Monarca las menciona como "mis reales fábricas de Guadalajara". 28 En 1746, continuaban activos dos molinos de papel que fabricaban anualmente 3.700 resmas para papeletas de pólvora, papel de imprenta, de estraza y estracilla. Posteriormente, en 1792, seguían en funcionamiento produciendo 400 resmas de papel fino y 6.000 de papel común, con precios de 28 reales por resma el primero y 22 el segundo.

El molino de papel Los Heros estaba situado en un caserío de mismo nombre sobre el río Dulce, a tres kilómetros del pueblo La Cabrera (Fig. 6), y suministró al impresor Juan de Ibarra, en 1755, papel para el catón, motivo de la interpelación anteriormente mencionada, cuando es llamado a declarar sobre la edición de un catón de dudosa calidad.

El molino del Paular o Rascafría (Fig. 6) estaba ubicado en el partido judicial de Torrelaguna (Madrid), sobre el río Lozoya, y pertenecía a los monjes de Scala Dei, que habían fundado en 1390, junto al rey Juan I, la Cartuja de El Paular. Se menciona a este molino en el siglo XVI, en un privilegio otorgado por Doña Juana. En una partida de 1605, se registra la venta, atribuida a la producción del molino, de papel blanco "de marquilla de Génova con un precio de 17 reales cada una" (HERRERO GARCÍA, 1958). Sin embargo, es considerable la diferencia del precio con las otras partidas del molino, que en 1599 costaban 11,5 reales, precio que variará mínimamente hasta 1646 . Con seguridad, el papel mencionado era importado de Génova, y no producido en el molino.

BALMACEDA-ABRATE, José Carlos. Dependencia y escasez de papel en las colonias hispanoamericanas. PÓS:Revista do Programa de Pós-graduação em Artes da EBA/UFMG. v. 11, n. 22, mai-ago. 2021 Disponível em < $\underline{\text { https://doi.org/10.35699/2237-5864.2021.25676 }>~}$ 


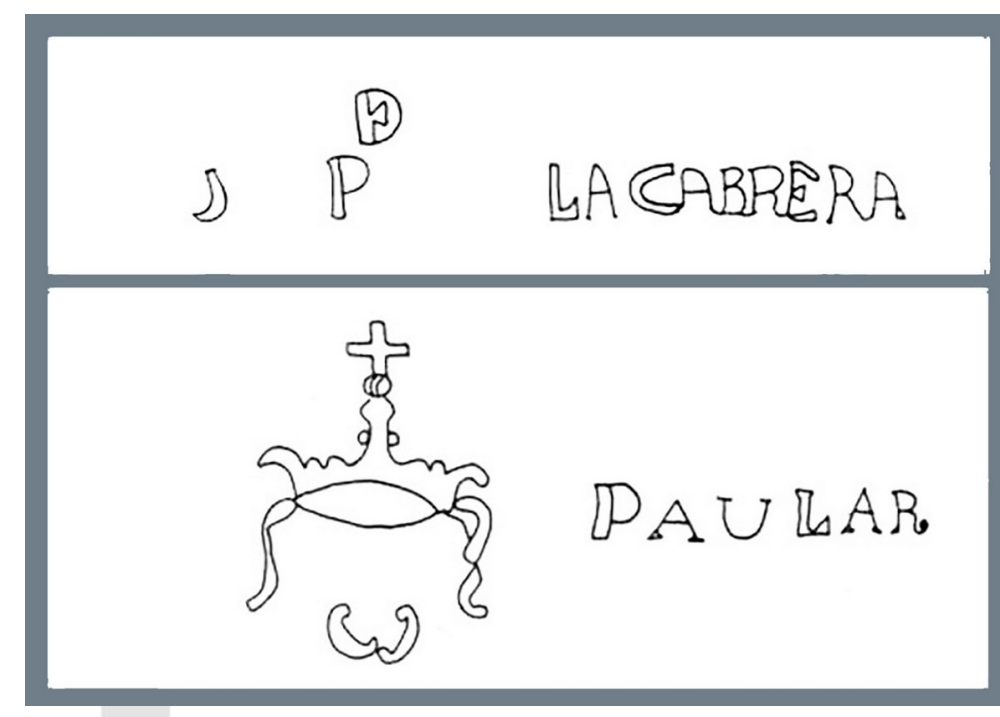

Fig. 6 - [Arriba]: Filigrana de un impreso de 1787 del molino de La cabrera. [Abajo]: Filigrana de un papel en blanco del molino de papel de El Paular, s/f. Fuente: Corpus de Gonzalo Gayoso Carreira (1994, t. II).

Por otra parte, los exámenes realizados del papel producido en el molino del Paular en los años 1602 y 1603, y usado en algunas publicaciones, señalan que se trataba de un papel basto, moreno, mal refinado, con motas, poros grandes, grumos gruesos e irregulares. Dicha calidad no mejoró en años posteriores, ya que, sobre el producido en 1673, se agrega que tiene pegotes; que visto por transparencia denuncia una forma muy deficiente; y que, por lo tanto, tiene más aspecto de papel estraza que de impresión (GAYOSO CARREIRA, 1994). La descripción concuerda con el impreso que expongo en la figura 7.

Según Jerónimo de Ustaríz, en 1724 el papel producido en El Paular había mejorado considerablemente la calidad, y como hemos visto, así lo consideran otras fuentes. Durante ese siglo, fabricaron papel florete y, como indica Ustaríz, el papel superior de segunda era mejor que el entrefino de segunda propiamente dicho, de imprenta, estraza y estracilla, y el blanco de segunda suerte era de muy buena calidad. Entre 1756 y 1773, el promedio de producción fue de 5.800 resmas, aunque del florete, que era el que más se necesitaba, se producían mínimas cantidades (50 resmas en 1756 y 60, 61 y 80 resmas en 1773). Más adelante, se generalizará la producción con la denominación de primera (blanco), de segunda y de tercera. La producción del último año mencionado fue de 2.500 , 2.900 y 1.300 respectivamente, donde la calidad "florete" se incluirá en la primera categoría. En

BALMACEDA-ABRATE, José Carlos. Dependencia y escasez de papel en las colonias hispanoamericanas. PÓS:Revista do Programa de Pós-graduação em Artes da EBA/UFMG. v. 11, n. 22, mai-ago. 2021 Disponível em < $\underline{\text { https://doi.org/10.35699/2237-5864.2021.25676 }>~}$ 
1780, el viajero Antonio Ponz (1781) escribe que de las 6.000 resmas que se producían, las integraban ocho clases de papel del más fino al más ordinario, sin contar el de estraza. Creo que confunde la calidad con los formatos.

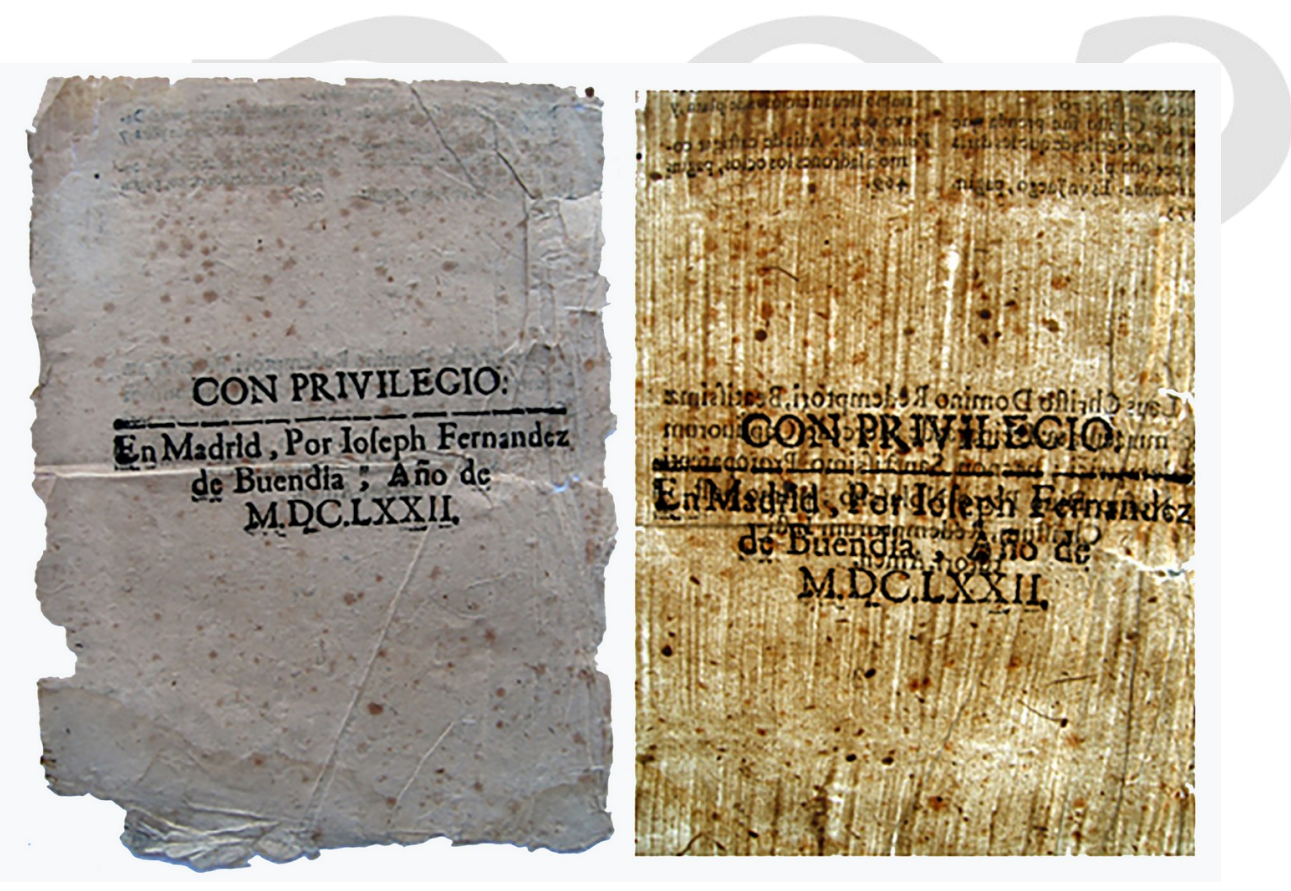

Fig. 7 [lzquierda]: Privilegio impreso en formato in-cuarto, en 1672, por Joseph Fernández de Buendía en Madrid. [Derecha]: La foto por transparencia nos muestra una forma deficiente: corondeles irregulares; puntizones separados y muy abiertos entre sí, con poca tensión; deficiente tratamiento de la pasta con restos de hebras textiles y partículas ácidas. Fuente: Fotos del autor.

En los molinos a orillas del río Tajo, en Toledo, desde antiguo se producía papel de estraza grueso, igual que el que se seguía haciendo en 1746. En el catastro del Marqués de la Ensenada (1750), se reconoce producción de papel en Toledo. No obstante, se cree que se trata de los molinos de Goyeneche y Solernou, y quizá también el del fabricante Llovet, en Ambite, que pertenecían en esa época a la provincia de Toledo, como ya hemos dicho. El catastro los da como de propiedad eclesiástica, por lo que podríamos creer que se refieren a los del río Tajo.

El molino de Joseph Solernou (Fig. 8) estaba equipado de dos ruedas hidráulicas, una batería de 24 pilas (con 3 mazos cada una) y dos tinas. Se encontraba a un cuarto de legua del molino de Goyeneche y producía, según la Real Cédula del 6 de noviembre de 1736, papel de las tres calidades, de las que presentaba muestras en que se reconocía que, no sólo igualaba, sino excedía al que llegaba

BALMACEDA-ABRATE, José Carlos. Dependencia y escasez de papel en las colonias hispanoamericanas. PÓS:Revista do Programa de Pós-graduação em Artes da EBA/UFMG. v. 11, n. 22, mai-ago. 2021 Disponível em $<\underline{\text { https://doi.org/10.35699/2237-5864.2021.25676 }}>$

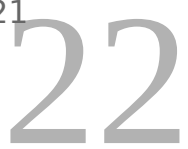


de Génova. Ese año, el presbítero Nicolás de Gozque hereda el molino (Fig.8) y recibe del rey, por 10 años, franquicias y gracias (para él, para los oficiales y demás obreros). Este molino producirá, por año, 4.000 resmas de las siguientes calidades: 1.000 de florete, 1.500 de blanco de segunda y 1.500 resmas de papel de imprimir. Se le prorrogan los privilegios en 1757, y en 1764 se los conceden a su hijo José de Gozque, que es el nuevo propietario.

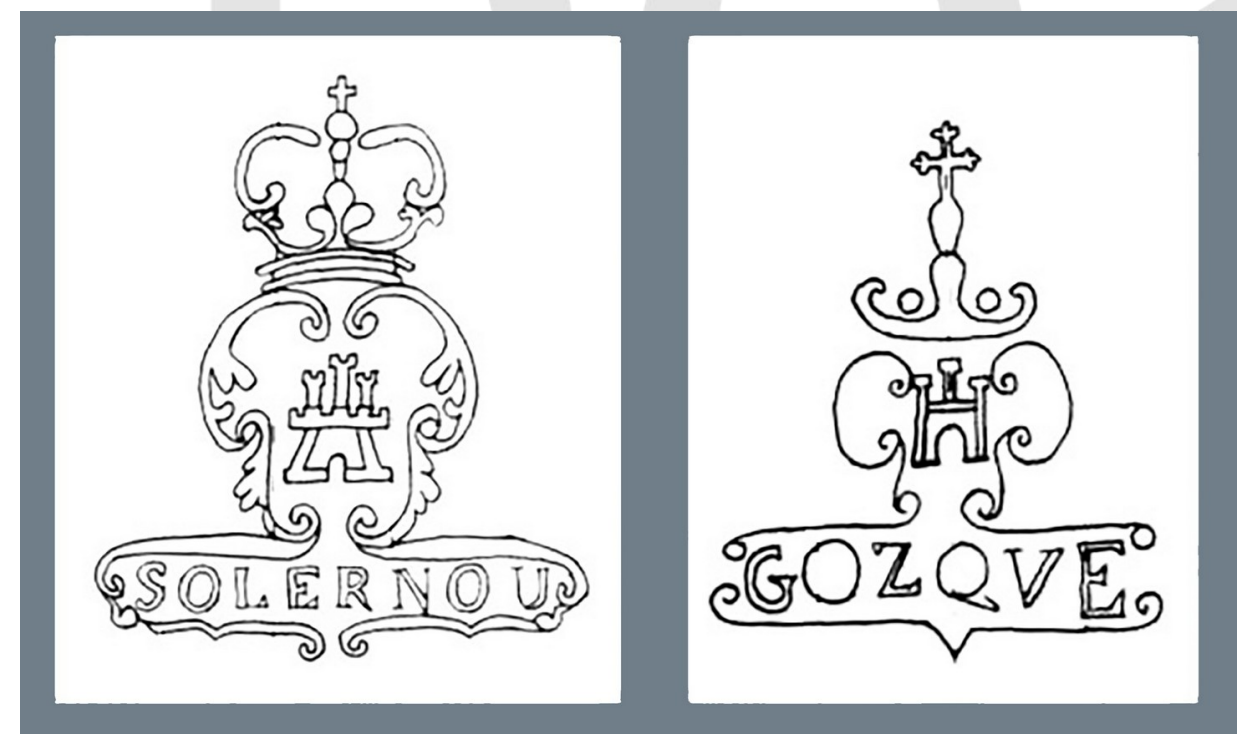

Fig. 8 - [lzquierda]: Filigrana de José Solernou en un impreso de 1769. [Derecha]: Filigrana de su hijo Nicolás de Gozque en un impreso de 1732. Fuente: Corpus de Gonzalo Gayoso Carreira (1994, t. II).

Cuando se menciona a los molinos de papel de Valladolid, las referencias apuntan a las antiguas fábricas del Monasterio Jerónimo de Nuestra Señora del Prado, que se inician en esta manufactura con el privilegio dado por los Reyes Católicos hacia 1493. Aquellas fábricas produjeron papel para la impresión de bulas de la Santa Cruzada, lo que motivó, además, la instalación de una imprenta. A Alonso del Riego, impresor del Santo Tribunal de la Inquisición y de la Real Universidad de Valladolid, se le concedió una prórroga, siendo éste propietario de un molino para fabricar papel que conservaba en la ribera del río Arlanzón (ALCOCER Y MARTíNEZ, 1993).

En Segovia, uno de los molinos, Ilamado "La Flecha", estaba ubicado en La Granja, precisamente en el arroyo de la Encomienda - ribera del río Pisuerga. El otro se ubicaba en el barrio de San Juan, sobre el río Esgueva. A principios del siglo XVIII, La Flecha producía un promedio de 4.293 resmas al año de papel para bulas, papel mezetta y papel de estraza (siendo la producción muy baja de estos dos últimos). En 1738, fabricó 4.700 resmas y llegó, en 1760, a las 5.000 resmas de papel para bulas.

BALMACEDA-ABRATE, José Carlos. Dependencia y escasez de papel en las colonias hispanoamericanas. PÓS:Revista do Programa de Pós-graduação em Artes da EBA/UFMG. v. 11, n. 22, mai-ago. 2021 Disponível em < $\underline{\text { https://doi.org/10.35699/2237-5864.2021.25676 }>~}$ 
En Zaragoza, hubo fabricación en el siglo XV (BALMACEDA, 2008). Según registra un documento de 1516, consta que se producía allí papel de estraza y para naipes - aunque el papel que menciona el impresor Ibarra era producido en la fábrica de la Compañía de Comercio, creada en 1746, que fabricaba papel blanco y de estraza (Fig. 9).
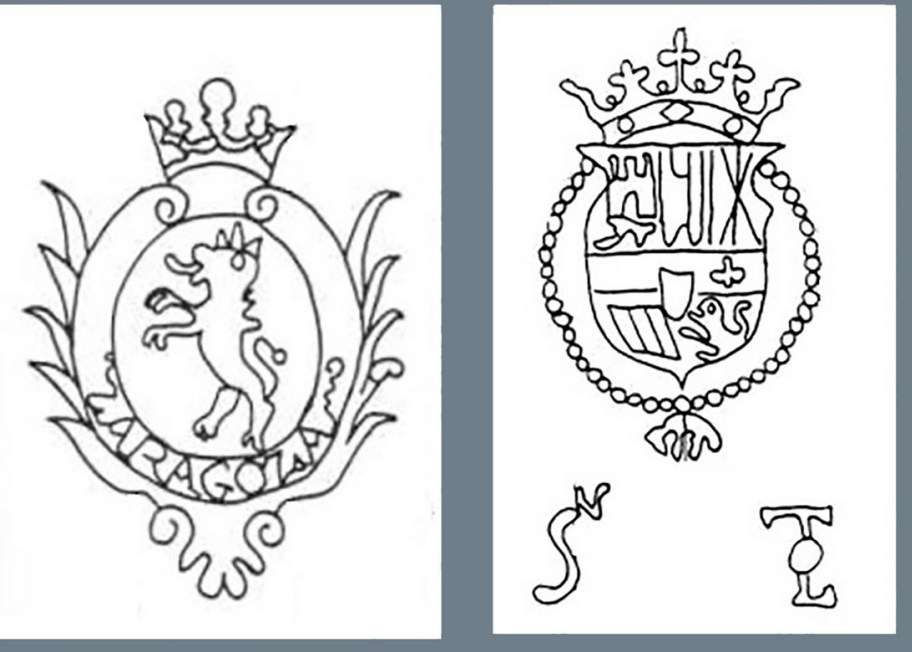

Fig. 9 - [lzquierda]: Filigrana de la fábrica de papel de Zaragoza en un impreso de 1753. [Derecha]: Filigrana de Sebastián Otonel, con las armas reales en un impreso de 1657. Fuente: Corpus de Gonzalo Gayoso Carreira $(1994$, t. II).

Sobre la fabricación en los molinos catalanes, José Soler generaliza el nombre de las fábricas a cuatro lugares, que ya hemos anotado anteriormente. Por otro lado, dos años antes del documento de López Oliver, el 5 de abril de 1728, un bando ordenado por el Intendente General de Cataluña, Joseph Contamina, nos lleva a una lista anexa con los molinos papeleros y las respectivas clases de papel que producían. Quince de ellos hacían papel blanco y siete papel estraza, repartidos como sigue: papel blanco - Girona (1), Banyoles (3), Olot (3), Les Planes (1), Sant Pere de Torelló (1), Sant Celoni (1), Ripollet (2), Sant Pere de Riudebitlles (2), Tarragona (1); papel de estraza - La Riba (4), Constantí (1), Barberá (1), Sant Pere de Riudebitlles (1). En los mismos años, Gutiérrez Poch (2001) contabiliza 35 molinos, entre los que se cuentan 6 en Capellades, 3 en la Pobla de Claramunt, 2 en la Torre de Claramunt y 3 en Carme.

BALMACEDA-ABRATE, José Carlos. Dependencia y escasez de papel en las colonias hispanoamericanas. PÓS:Revista do Programa de Pós-graduação em Artes da EBA/UFMG. v. 11, n. 22, mai-ago. 2021 Disponível em < $\underline{\text { https://doi.org/10.35699/2237-5864.2021.25676 }}>$ 


\section{Franquicias, gracias y privilegios}

La política mercantilista de la primera mitad del siglo XVIII se caracterizó por el mantenimiento de la legislación favorable a las corporaciones gremiales; el fomento de la industria mediante la concesión de privilegios de monopolio; la creación manufacturera estatal; y el proteccionismo en el comercio exterior (GONZÁLEZ ENCISO, 1980). Fue en este contexto que los Borbones intentaron renovar la industria siguiendo un ambicioso plan de manufacturas reales, como en otras monarquías europeas, aunque los resultados en España no fueron muy alentadores como en la vecina Francia.

En el siglo anterior, ya se habían concedido la exención de impuestos a varios genoveses, que comprendía alcabalas, cientos y demás derechos (como los que se pagaban en puertos, portazgos y puertas). En Cuenca, Juan Otonel y sus sucesores quedaron exentos de oficios, cargas del consejo y repartimientos municipales (Fig. 9). Además, en 1639 se le otorgó, a cargo de la Real Cédula, la exclusividad de la venta de su papel en la ciudad capital y en la provincia de Cuenca y sus alrededores (hasta los 80 kilómetros).

Los proyectos industriales de Juan de Goyeneche intentaron solucionar los principales problemas de la España de principios del siglo XVIII, y en concreto el escaso desarrollo industrial y los efectos de la recesión demográfica de esos años. Goyeneche, tesorero de la Reina, había obtenido, por compra del hospital general, el privilegio de impresión de la Gaceta, derecho que Felipe V renovará a su nombre el 22 de octubre de 1701 - aunque él también se sirvió de personal extranjero especializado. Los directivos de la fábrica de paños en Olmeda, por ejemplo, eran de origen francés, y también los maestros del tinte, los de tundir y cardar. Esta fábrica tuvo un privilegio real que le dispensó del pago de impuestos durante 30 años, dentro de la línea general de proteccionismo y de concesión de privilegios que caracterizó a la industria de las primeras décadas del siglo. Igualmente, se trajeron maestros franceses para instruir a los naturales y dirigir cada una de las otras fábricas, especialmente la de sombreros.

El 6 de octubre de 1714, Francineto Piombino recibió franquicias de alcabalas, cientos y millones para él, sus herederos y su personal, además de la exclusividad por veinte años de la venta del papel en la región gallega.

BALMACEDA-ABRATE, José Carlos. Dependencia y escasez de papel en las colonias hispanoamericanas. PÓS:Revista do Programa de Pós-graduação em Artes da EBA/UFMG. v. 11, n. 22, mai-ago. 2021 Disponível em $<\underline{\text { https://doi.org/10.35699/2237-5864.2021.25676 }}>$

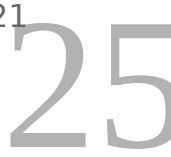


Joseph Solernou recibió las mismas exenciones, franquicias y libertades que Juan Otonel y Juan de Goyeneche, que gozaron para sus fábricas de papel de Cuenca y del Nuevo Baztán la dispensa de alcabalas, cientos, puertas, portazgos, puentes, además de los demás derechos y contribuciones reales y municipales. Estos privilegios le serán renovados, el 6 de noviembre de 1736, a su heredero, Nicolás de Gozque, extensivos a sus oficiales y obreros, y continuarán favoreciendo a su hijo, José de Gozque, en 1757 y en 1764 con una duración de 10 años. Además, se autorizó a Nicolás a poner el escudo de armas en el papel que fabricase y en la lonja que lo vendiere en Madrid - el escudo de las reales armas, con la inscripción de Real Fábrica de Papel de la villa de Oruzco.

Diego Ramírez de Loaysa, por su parte, también recibirá privilegios en sus molinos de La Adrada (Ávila), otorgados por Felipe V en la Real Cédula del 24 de mayo de 1714.

En 1735, se conceden excepciones y franquicias para la fábrica de papel de los hermanos José y Tomás Romaní, de Capellades (Barcelona). Se desprende de esta Real Cédula que los dos molinos abastecían papel a las oficinas de Cataluña, Madrid y otros lugares. La Audiencia les había dado permiso para poner en la marca la calidad del papel, evitando así la falsificación. Además de ello, los Romaní fabricaban papel blanco común, imprenta, marquilla y marca mayor. Asimismo, se reconoce en la Cédula que estos fabricantes imitaban los papeles de Francia y Génova, utilizando, además, la filigrana de los dos o tres círculos. Se les concedió por diez años, o sea, hasta 1745, la prioridad para comprar los trapos y otros materiales en todas las ciudades, villas y lugares del reino sin pagar derechos y portazgos - impuesto indirecto que grababa el tráfico de mercaderías y las transacciones realizadas en los mercados - y la preferencia en el tanteo de trapos. También se les permitió el uso de armas en el escudo sobre la puerta del molino con la inscripción: Fábrica Real de Papel de Capellades.

En 1740, los Romaní habían duplicado los molinos de su propiedad, produciendo papel imperial, marca mayor, marquilla, florete fino, de imprenta y algo llamado "patracol", que sería la forma familiar de llamar a un libro grueso, un mamotreto o un libraco en blanco. José Romaní, además, hacía cartones para prensar paños y papel azul para el azúcar y otros envoltorios. Este año, se le renovaron las mismas franquicias hasta 1750 por Real Cédula, donde se reconocía que la calidad del papel excedía en las más de sus suertes al mejor de Génova. ${ }^{29}$

BALMACEDA-ABRATE, José Carlos. Dependencia y escasez de papel en las colonias hispanoamericanas. PÓS:Revista do Programa de Pós-graduação em Artes da EBA/UFMG. v. 11, n. 22, mai-ago. 2021 Disponível em < $\underline{\text { https://doi.org/10.35699/2237-5864.2021.25676 }}>$ 
En 1770, se continuaba aplicando parcialmente privilegios, como lo muestran las resoluciones del Consejo (del 23 de mayo de 173) o de la Real Cédula (del 21 de junio de 1773), ${ }^{30}$ que concedían privilegios reales a los hermanos Francisco y Pedro Guarro, de la Puebla de Claramunt, provincia de Barcelona, proveedores de papel a las secretarías y otras oficinas reales. Basándose en el consumo de papel marquilla que hacía el hijo del monarca, se les concede a los Guarro, por el tiempo de diez años, el uso del escudo de las armas reales y el título de fábrica real; libertad de derechos sobre la compra del trapo, de la carnaza y de la cola; privilegio de tanteo; y libertad de derecho en las primeras ventas que hicieran por su cuenta. Por fin, el desarrollo de la industria española será una realidad, aunque insuficiente, como veremos.

Finalmente, Carlos III generalizará privilegios el 26 de octubre de 1780 con otra Real Cédula, ${ }^{31}$ otorgando franquicias y gracias diversas para el fomento y la instalación de fábricas de papel en España. Esta medida va a generar la reactivación de esta manufactura y la instalación y apertura de fábricas en nuevas regiones españolas, especialmente Andalucía (BALMACEDA, 1998; 2001; 2004).

\section{Conclusión}

Resulta imposible intentar una conclusión sobre un tema tan extenso, complejo y apasionante como es este periodo de la historia del papel en España. En este artículo, se exponen una sucesión de requerimientos que indican la necesidad de incrementar la producción y lograr calidad en la fabricación del papel. Desde el siglo XVI, y dentro del propósito monopolista de la corte madrileña, siempre estuvo presente la elección del papel extranjero - en vez del desarrollo del nacional (escaso y en general de baja calidad) -pretendiendo, desde un primer momento, beneficiarse con la subordinación económica y establecer una situación de privilegio para la Corona.

Durante el siglo XVII y en más de la mitad del XVIII, se hace referencia - en documentos de instituciones religiosas, de asociaciones civiles y de impresores implicados en el consumo de este producto - a la buena calidad del papel genovés, solicitando que se trasladen maestros papeleros ligures a fin de mejorar la calidad del producido en los molinos españoles, exigiendo, además, que ellos transmitan sus conocimientos a los papeleros y aprendices locales.

BALMACEDA-ABRATE, José Carlos. Dependencia y escasez de papel en las colonias hispanoamericanas. PÓS:Revista do Programa de Pós-graduação em Artes da EBA/UFMG. v. 11, n. 22, mai-ago. 2021 Disponível em < $\underline{\text { https://doi.org/10.35699/2237-5864.2021.25676 }>}$ 
Éstos y sus descendientes han estado presentes desde el siglo XV principalmente como proveedores de este producto. Del mismo modo, muchos maestros fueron los responsables de la construcción e instalación de fábricas y, por lo tanto, del origen de esta manufactura en algunas regiones de la Península. Algunas de ellas, incluso, se convertirán en esenciales después de las transformaciones históricas y políticas que hicieron eclosión en el XVIII, obligando a los Borbones a realizar una serie de reformas en contradicción con el viejo espíritu y el sistema establecido.

Existen valiosas publicaciones sobre las relaciones políticas, sociales y comerciales entre ambos Estados, pero el papel, tema de nuestro interés, siempre ha sido marginado a mínimos periodos ante otras manufacturas y asuntos que fueron y son todavía considerados más importantes en el contexto económico.

No obstante, es indiscutible la relación de dependencia que se mantuvo durante siglos con banqueros europeos, en particular, durante mucho tiempo, con los mercaderes genoveses. Consecuentemente, ellos se convierten en los proveedores casi exclusivos de papel, no sólo el que se producía en Génova, sino también el de otras regiones italianas. Prueba de todo lo dicho es su presencia mayoritaria como soporte documental en Hispanoamérica.

Las reformas que afectaron al comercio del papel genovés con España fueron la consecuencia del desarrollo, aunque parcial, del comercio del papel español con las colonias y también de las franquicias y gracias, excepciones de impuestos y preferencias - en el tanteo y compra del trapo - a los fabricantes locales.

Sin embargo, a pesar del esfuerzo y de la evolución en calidad y cantidad de la producción española, en las primeras décadas del XIX - legal o ilegalmente en las independizadas colonias americanas - se disponía de toda clase de papel a precios competitivos, procedentes de los más variados centros productores de Europa. Las principales potencias rivales de España, principalmente Inglaterra, que ingresaba en la etapa del maquinismo y de la Revolución Industrial, traerán algunos momentos de abatimiento en las fábricas peninsulares. Por su parte, las fábricas de Génova seguirán exportando directamente a las independizadas repúblicas y fabricando papel por encargo de los Estados, instituciones oficiales y privadas.

BALMACEDA-ABRATE, José Carlos. Dependencia y escasez de papel en las colonias hispanoamericanas. PÓS:Revista do Programa de Pós-graduação em Artes da EBA/UFMG. v. 11, n. 22, mai-ago. 2021 Disponível em < https://doi.org/10.35699/2237-5864.2021.25676 $>$ 


\section{REFERÊNCIAS}

AA. VV (VARIOS AUTORES). Guarro Casas, 300 anys d'història - 1698-1998. Barcelona: Guarro Casas, 1998.

AA. VV (VARIOS AUTORES). Juan Párix: primer impresor en España. Segovia: Fundación Instituto Castellano y Leonés de la Lengua; Caja Segovia, 2004.

ALCOCER Y MARTÍNEZ, Mariano. Catálogo razonado de obras impresas en Valladolid - 1481-1800. Valladolid: Ed. Junta de Castilla y León; Consejería de Cultura y Turismo, 1993.

BALMACEDA, José Carlos. Apuntes para el estudio del papel y las filigranas durante el siglo XV en la Corona de Aragón. Revista Aragón en la Edad Media, Zaragoza, n. 20, p. 103-116, 2008.

BALMACEDA, José Carlos. El uso del papel en América: papel autóctono y papel importado. In: XI CONGRESO NACIONAL DE HISTORIA DEL PAPEL EN ESPAÑA (AHHP), 11., 2015, Sevilla. Actas del $11^{\circ}$ AHHP. Sevilla: Departamento de Publicaciones Ayuntamiento de Sevilla, 2015. p. 33-45.

BALMACEDA, José Carlos. Estudio de las formas y filigranas de una edición boloñesa de 1680 . Revista Pátina, Madrid, n. 16, p. 161-172, 2011.

BALMACEDA, José Carlos. La contribución genovesa al desarrollo de la manufactura papelera española. Málaga: Centro Americano de Historiadores del Papel, 2004. (Colección Apapiris)

BALMACEDA, José Carlos. Las filigranas de los primeros impresos de Buenos Aires. In: 24th INTERNATIONAL CONGRESS OF PAPER HISTORIANS (IPH), 24., 1998, Oporto. Actas del 24ㅇ IPH - v. 12. Birkerød (Dinamarca): IPH, 1998. p. 220-255.

BORDÁZAR DE ARTAZU, Antonio. Planificación de la imprenta del rezo sagrado - 1732 (Edición facsímile). Valencia: Ayuntamiento de Valencia, 1997.

CALEGARI, Manlio. La manifattura genovese della carta - Sec. XVI-VIII. Génova: E.C.I.G. Edizioni Culturali Internazionali Genova, 1986.

CERVERA VERA, L. "Documentos relativos a las estampas del Monasteerio de San Lorenzo el Real de El Escorial" en L:C.D CLXIV, nº. 2, 1952, p. 352 y ss...

COMELLAS, José Luis. Sevilla, Cádiz y América: el trasiego y el tráfico. Málaga: Ed. Arguval, 1992. (Colección Tres Culturas).

GALLEGO, Antonio. Historia del grabado en España. Madrid: Cuadernos Arte Cátedra, 1999.

GARCÍA FUENTES, L. El comercio español con América, 1650-1700. Diputación provincial de Sevilla, 1980.

GAYOSO CARREIRA, Gonzalo. Historia del papel en España - tres tomos. Lugo: Servicio Publicaciones Diputación Provincial de Lugo, 1994.

GONZÁLEZ ENCISO, Agustín. Estado e industria en el siglo XVIII: la fábrica de Guadalajara. Madrid: Fundación Universitaria Española, 1980.

BALMACEDA-ABRATE, José Carlos. Dependencia y escasez de papel en las colonias hispanoamericanas. PÓS:Revista do Programa de Pós-graduação em Artes da EBA/UFMG. v. 11, n. 22, mai-ago. 2021 Disponível em < $\underline{\text { https://doi.org/10.35699/2237-5864.2021.25676 }>~}$ 
GUTIÉRREZ I POCH, Miquel. Full a full, la indústria papelera de l'Anoia - 1700-1998. Barcelona: Publicacions de L'abadia de Monserrat, 1999.

HERRERO GARCÍA, Miguel. El Molino del Paular. El libro español - Revista mensual del Instituto Nacional del Libro Español, Madrid, n. 4, p. 167-172, 1958.

IZQUIERDO, F. Xilografía granadina del siglo XVII, Madrid. 1975.

LENZ, Hans. Historia del papel en México y cosas relacionadas - 1525-1950. CDMX: Editora Miguel Ángel Porrúa, 1990.

LLAGUNO Y AMIROLA, Eugenio. Noticias de los arquitectos y arquitectura de España desde su restauración, v. II. Madrid: Imprenta Real, 1829.

LÓPEZ OLIVER, Francisco. Demostración apologética de la verdad contenida en la representación humilde que... (Imprenta de Antonio Bordazár, 1730). Ed. Facsímil. Valencia: Ayuntamiento de Valencia, 1997.

LÓPEZ OLIVER, Francisco. Representación humilde al Rey Ntro. Sr. y manifiesto claro de la razón y justicia del Estado Eclesiástico de las dos coronas de Castilla y León, por quien se propone a Su Majestad, para el bien público de estos Reinos, lo que se discurre conveniente en orden a establecer en España la imprenta del Nuevo Rezado. (Imprenta de Antonio Bordazár, 1729). Ed. facsímil. Valencia: Ayuntamiento de Valencia, 1997.

MADURELL I MARIMON, Josep Maria. El paper a les terres catalanes. Contribució a la seva história - v. 1 e 2. Barcelona, 1972.

MARTÍNEZ DE SALINAS, María Luisa. La implantación del impuesto del papel sellado en Indias. Caracas: Academia Nacional de la Historia, 1986.

MOUTOUKIAS, Zacarías. Contrabando y control colonial en el siglo XVII: Buenos Aires, el Atlántico y el espacio peruano. Buenos Aires: Centro Editor de América Latina, 1988. (Bibliotecas Universitarias).

REYES GÓMEZ, Fermín de los. El libro en España y América: legislación y censura (siglos XV-XVIII), t. I y II. Madrid: Arco/Libros S.L, 2000. (Instrumenta Bibliológica)

RUIZ DE ARCAUTE, Agustín. Juan de Herrera: arquitecto de Felipe II. Madrid: Espasa-Calpe, 1976.

VILLALOBOS, Sergio R. Comercio y contrabando en el Río de la Plata y Chile - 1700-1811. Buenos Aires: EUDEBA, 1986. (Biblioteca de América/Libros del Tiempo Nuevo)

BALMACEDA-ABRATE, José Carlos. Dependencia y escasez de papel en las colonias hispanoamericanas. PÓS:Revista do Programa de Pós-graduação em Artes da EBA/UFMG. v. 11, n. 22, mai-ago. 2021 Disponível em < $\underline{\text { https://doi.org/10.35699/2237-5864.2021.25676 }>}$ 


\section{NOTAS}

1 Los primeros periódicos aparecen en los Países Bajos y Alemania entre 1597 y 1605.

2 Gallego cita 4.000 estampas por cada plancha, o sea, un total de 52.000 grabados (p. 64). Esta enorme cantidad ha sido registrada anteriormente por los autores L. Cervera Vera (1952) y Ruiz Arcaute (1976).

3 Las medidas de los formatos más usados eran: blanco ordinario/320 x 450mm; marquilla/390 x 550mm; marca mayor $/ 470 \times 680 \mathrm{~mm}$; imperial $/ 520 \times 770 \mathrm{~mm}$.

4 Compromís per a la renda de paper d'estampa. Dicto die VIII. Mensis decembris (1683). AHPB (Archivo Histórico Provincial de Barcelona). Buenaventura Vita, llig. 17 (2॰ parte). Cancellat a 29 decembre 1694. Y Dicto die (10 abril 1703). AHPB (Archivo Histórico Provincial de Barcelona). Josep Madriguera, llig. 2, man. Año 1703, f. 134 gir.

5 Respuesta de Fr. Eugenio de la Llave, Prior de El Escorial, a la pretensión de nacionalización de la impresión de libros de rezo por Felipe V. Archivo Palacio San Lorenzo.

6 Fr. Eugenio de la Llave, Respuesta a D. José Rodrigo de Villalpando a la pretensión del Rey sobre N.R. 1717. (1729). Archivo Palacio San Lorenzo, Leg. 59.

7 Ídem. Leg. 59.

8 Sevilla, Cartagena, Cuenca, Ciudad Rodrigo, Palencia, Plasencia, Astorga y Canarias.

9 Informe de Juan de la Puebla en virtud del Decreto de 16 de abril de 1732. AHN (Archivo Histórico Nacional). Ms. 724, f. 1-24.

10 Reseña histórica en forma de diccionario de las imprentas que han existido en Valencia. Publicado por José Enrique Serrano (p. 335-387).

11 Un memorial de José de Orga sobre el Nuevo Rezado. AHN (Archivo Histórico Nacional). Consejos. Leg. 11275.1749 .

12 Orden de S. M. para que las impresiones se hagan en papel fino semejante al de las fábricas de Capellades. AHN (Archivo Histórico Nacional). Consejos. Libro 1338, f. 309.

13 Reglas que deben observar los impresores y libreros para la impresión y venta de libros conforme a lo dispuesto por las leyes del Reino. Novísima Recopilación. Libro VIII. Título XVI. Ley XXIV. Novísima Recopilación. Libro VIII. Título XVI. Ley XXIV. AHN (Archivo Histórico Nacional).

14 Memoria de los impresores de Madrid y Sevilla para que se les permita concluir las impresiones en papel ordinario hasta acabar con el que tengan. 5 de julio de 1751. Archivo San Ginés. San Jerónimo. Pleitos y documentos. 69. Madrid.

15 AHN (Archivo Histórico Nacional). Consejos, Leg. 50690, Madrid.

16 AGS (Archivo General de Simancas). Consejos y Junta de Hacienda, Leg. 750, Salinas, óp. cit, Pág. 86.

17 AGS (Archivo General de Simancas). Contaduría general, Leg. 2707.

18 El Gobernador y Capitán General de Filipinas dan cuenta de la acogida que tuvo en las islas el Papel Sellado y de por qué se selló el papel con papel de la China. AGI (Archivo General de Indias). Indiferente General, Leg. 79, 28 de julio de 1642.

19 Scacuola, además de querer imponer la forma de cobrarse su aporte económico, pedía una encomienda para su hijo. AGS (Archivo General de Simancas). Juntas de Hacienda, Leg. 770, Salinas, óp. cit., Pág. 122.

20 Los Grasso eran importantes comerciantes y propietarios de fábricas de papel en Voltri. En 1612, Bartolomeo y su sobrino, Giuseppe, controlaban 9 fábricas en Leira, 2 en Gorsexio y 2 en Cerusa. En 1633, documentamos a G. Gerolamo Grasso con fábricas de papel en Mele (Génova). Gian Battista continúa la tradición familiar en 1683.

21 "Que el dicho papel haya de ser bueno de dar y recibir, y que no se pase con tres manos de costeras en cada resma, que es en la forma que viene de la ciudad de Génova y es uso y costumbre de venderse en esta Corte". Condiciones de Nicolás Graso para traer de Génova el papel blanco para sellar. AGS (Archivo General de Simancas). Contadurías Generales, Leg. 2706, 26 de junio de 1637.

22 Los balones genoveses de papel blanco de escribir llegados a Murcia entre 1598 y 1602 se componían de 20, 22 y 24 resmas cada uno. La bala se componía de 10 o 12 resmas.

23 El pliego es el papel que se hace en la forma manual y que luego se divide en dos hojas (Fig. 4). Un cuadernillo está compuesto por 5 pliegos, y una mano, por 25 pliegos o 5 cuadernillos. Cada resma se componía de 500 pliegos o 20 manos. Las manos ubicadas en los extremos de la resma se llaman costeras.

24 AGS (Archivo General de Indias). Indiferente General, Leg. 1739.

25 AGS (Archivo General de Simancas). Hacienda, Leg. 2335. 


\section{NOTAS}

26 Trabajaban en este molino 30 personas. Para que no careciera, en los días de fiesta, el precepto del beneficio de la misa, mandó el poseedor de este mayorazgo a poner una señal por donde los obreros del molino fueran avisados cuando se decía la misa. AHPM (Archivo Histórico Provincial de Madrid). Prot. $\mathrm{n}$. 16.161, testamento de Juan de Goyeneche, f. 71-79.

27 En la genealogía publicada por la empresa Guarro Casas, no figura ningún Guarro con ese nombre.

28 Real Cédula de franquicias a favor de los hermanos J. y T. Romaní. ACA. RP. Registro Superintendencia General, 1,27. 1749, f. 870.

29 Ídem. Registro Superintendencia General, 1,17, año 1749 y 870/7. Ídem, doc. n. 137, Pág. 1125.

30 ACA (Archivo de la Corona de Aragón). R.P. Superintendencia General, 1773, Reg. 1/31.

31 Ídem. Doc. 149. p. 1154-1159. 